\title{
Attitude, Behavior and Oral Health among Patients Visiting a Dental Institution of Nepal
}

\author{
Sirjana Dahal, ${ }^{1}$ Prakash Poudel, ${ }^{2}$ Nirma Khadka, ${ }^{1}$ Sangita Dahal, ${ }^{1}$ Manita Acharya, ${ }^{1}$ Supriya \\ Shrestha, ${ }^{1}$ Manita Maharjan ${ }^{1}$ \\ ${ }^{1}$ Department of Community and Public Health Dentistry, ${ }^{2}$ Department of Orthodontics and Dentofacial Orthopaedics, \\ Kathmandu Medical College-Teaching Hospital, Duwakot, Bhaktapur, Nepal.
}

\begin{abstract}
Background: Majority of oral diseases are related to life style, which means that a behavioural change is needed to reduce the disease. This study was conducted to assess the attitude, behaviour and oral health of the patients visiting a dental hospital and to determine the association of oral health with age and gender.

Methods: Analytical cross-sectional study was conducted among 130 patients of age 15 years and above who visited Kathmandu Medical College, Bhaktapur for oral health check-up. Participants were interviewed for their attitude and behavior regarding oral health. Caries experience and periodontal conditions were assessed. Chi square test was done to evaluate the association of age and gender with of attitude, behavior and oral health.

Results: In this study, significantly higher number of females went to visit dentist when they noticed bleeding gums than males $(p=0.023)$. Tobacco was consumed more by males than females $(p<0.001)$. Mean DMFT was 3.85 \pm 3.035 . Bleeding on probing was found in $84(64.6 \%)$; calculus in $24(18.5 \%)$ and periodontal pocket of $\geq 4 \mathrm{~mm}$ in $11.6 \%$. Loss of attachment of $4 \mathrm{~mm}$ or more was present in $45(34.6 \%)$ and was significantly higher in older age group $(p<0.001)$; in males $(p=0.001)$; who were negligent in visiting dentist $(p=0.035)$; brushed by vertical method $(p=0.013)$ for less than two minutes and more than five minutes $(p=0.015)$; used toothpicks or no interdental cleaning aids $(p=0.009)$; ignored bleeding gums $(\mathrm{p}=<.001)$ and who used tobacco products $(\mathrm{p}<0.001)$.
\end{abstract}

Conclusions: This study concluded that the attitude towards the oral health was positive among the patients who visited Kathmandu Medical College, Bhaktapur, Nepal. The oral health behaviour was quite unsatisfactory and needs to be improved.

Keywords: attitude; behavior; oral health.

\section{INTRODUCTION}

American Dental Association defines Oral Health as a functional, structural, aesthetic, physiologic and psychosocial state of well-being and is essential to an individual's general health and quality of life. ${ }^{1}$ Improvement of oral health can be beneficial for overall health status of the patient. ${ }^{2}$

Oral health is the standard of health of the oral and related tissues. It enables individual to eat, speak and socialize without active disease discomfort or embarrassment which contributes to general well-being. There have been rapid changes in pattern of oral disease during the past decade. ${ }^{3}$ Oral disease can be considered a public health problem due to its high prevalence and significant social impact. ${ }^{3}$ The changing way of living and the pattern of oral diseases during past few decades clearly denote that there is effect of lifestyle, attitude and behavior on individual's oral health. Hence, behavioural change is needed to reduce the disease.
In developing countries like Nepal where there is inadequate focus on oral health, it is important to change the individual's perception and behavior towards oral health. Therefore, this study was conducted to assess the attitude, behavior and oral health of the patients visiting a dental hospital and association of age and gender with their existing oral health.

\section{METHODS}

An analytical cross-sectional study was conducted among patients who visited Kathmandu Medical College, Dental Hospital, Duwakot, Bhaktapur for oral health check-up. Convenience sampling technique was used to select 130 patients of fifteen years and above from September to December 2018. A protocol was submitted to the institutional review committee of Kathmandu Medical College and Teaching Hospital, Kathmandu, Nepal and ethical clearance was obtained. Participants were

Correspondence: Dr. Sirjana Dahal, Department of Community and Public Health Dentistry, Duwakot, Bhaktapur, Nepal. Email: sirjanadahal11@gmail.com. Phone: +977-9847279427. Article received: 201902-07. Article accepted: 2020-01-23. 
informed about the study and assured that their participation was truly voluntary and written informed consent was taken. Sample size has been calculated using formula, Sample size $(n)=z^{2} p q /$ $\mathrm{e}^{2}$. Where, $\mathrm{p}=$ prevalence of condition, $\mathrm{q}=1-\mathrm{p}, \mathrm{e}=$ margin of error taken as $10 \%$ (absolute error). Regarding prevalence of condition, data was taken from a study done in a dental hospital of Nepal (participants brushing twice daily). ${ }^{6}$ Actual Sample Size $(\mathrm{n})=3.84 * 65 * 35 /(10)^{2}=87.36$. Adding $20 \%$ of non-response, total sample $=104.83 \approx 130$ (taken).

\section{Inclusion criteria}

Patients visiting of Kathmandu Medical College ( $\geq 15$ years) for oral health check up and mentally sound patients.

\section{Exclusion criteria}

Patients having any developmental disability, frail elderly and patients under any medication affecting Oral Health.

Participants were interviewed for their attitude and behaviour regarding maintenance of oral health. Questions were taken from previously published studies. ${ }^{3,6,7}$ Pilot study was conducted among 10\% of the sample which was not included in the main study and modifications were made in the questionnaire where responses were not appropriate. Cronbach's alpha was used to check the internal consistency of the questionnaire and was good $(\alpha=0.82)$. Mouth mirror, Shepherd's Hook explorer and WHO probe was used for oral examination. Oral health was examined using DMFT for assessing caries experience and Community Periodontal Index for periodontal conditions.
Cohen's kappa was used for assessing inter examiner reliability. Data were entered in Microsoft Excel Sheet and analysis were done in Statistical Package of Social Sciences (SPSS) version 20. Mean, standard deviation, median, range, percentage were calculated for descriptive statistics. For inferential statistics, Chi-square test was done to see the association of attitude and behaviour with oral health.

\section{RESULTS}

Out of 130 respondents, $49(37.69 \%)$ were male and $81(62.31 \%)$ were female and their mean age was $35.95 \pm 16.23$ years (median $=28.50$ years). The caries experience of the participants (DMFT) was $3.85 \pm 3.035$ (median=3). Among them, mean number of decayed teeth were highest $(2.28 \pm 2.121)$ than filled $(0.91 \pm 1.507)$ and missing teeth $(0.68 \pm 1.725)$. On examination of periodontal condition using highest Community Periodontal Index scored, majority of the study participants had bleeding on probing 91(64.6\%) followed by supra or sub-gingival calculus $24(18.5 \%)$ and periodontal pocket of $\geq 4 \mathrm{~mm} 15(11.6 \%)$. Loss of attachment of $4 \mathrm{~mm}$ or more was present in 45 $(34.6 \%)$ of the total study population (score 1-4).

Table 1 and 2 shows the attitude and behavior of males and females with regard to oral health. Significantly higher number of females went to visit dentist when they noticed bleeding on probing than males $(p=0.023)$. Tobacco was consumed more by males in comparison to females $(\mathrm{p}<0.001)$. No significant association of age and gender was

\begin{tabular}{|c|c|c|c|c|c|}
\hline \multirow{2}{*}{ Question } & \multirow{2}{*}{ Options } & \multirow{2}{*}{$\begin{array}{c}\text { Total no. of } \\
\text { participants }\end{array}$} & \multicolumn{2}{|c|}{ Gender } & \multirow{2}{*}{$P$ value } \\
\hline & & & Male $(n=49)$ & Female $(n=81)$ & \\
\hline \multirow{3}{*}{$\begin{array}{l}\text { Regular dental visit is } \\
\text { necessary to prevent } \\
\text { dental problems }\end{array}$} & Agree & $114(87.69)$ & $42(85.7)$ & $72(88.9)$ & \multirow{3}{*}{$0.548^{\mathrm{a}}$} \\
\hline & Disagree & $7(5.38)$ & $2(4.1)$ & $5(6.2)$ & \\
\hline & Don’t know & $9(6.92)$ & $5(10.2)$ & $4(4.9)$ & \\
\hline \multirow{3}{*}{ Reasons behind brushing } & Clean, bright teeth & $51(39.23)$ & $20(40.8)$ & $31(38.3)$ & \multirow{3}{*}{$0.673^{\mathrm{a}}$} \\
\hline & Preventing foul smell & $28(21.53)$ & $12(24.5)$ & $16(19.8)$ & \\
\hline & Preventing caries, bleeding gums & $51(39.23)$ & $17(34.7)$ & $34(42)$ & \\
\hline \multirow{3}{*}{$\begin{array}{l}\text { Cleaning teeth prevents } \\
\text { tooth decay }\end{array}$} & Yes & $107(82.30)$ & $42(85.7)$ & $65(80.2)$ & \multirow{3}{*}{$0.686^{\mathrm{b}}$} \\
\hline & No & $11(8.47)$ & $4(8.2)$ & $7(8.6)$ & \\
\hline & Don't know & $12(9.23)$ & $3(6.1)$ & $9(11.1)$ & \\
\hline \multirow{3}{*}{$\begin{array}{l}\text { Oral health is related to } \\
\text { systemic health }\end{array}$} & Yes & $82(63.07)$ & $28(57.1)$ & $54(66.7)$ & \multirow{3}{*}{$0.572^{\mathrm{a}}$} \\
\hline & No & $22(16.93)$ & $10(20.4)$ & $12(14.8)$ & \\
\hline & Don't know & $26(20)$ & $11(22.4)$ & $15(18.5)$ & \\
\hline \multirow{4}{*}{$\begin{array}{l}\text { Dental care should be } \\
\text { received from }\end{array}$} & Dental hospital & $92(70.77)$ & $38(77.6)$ & $54(66.7)$ & \multirow{4}{*}{$0.422^{\mathrm{b}}$} \\
\hline & Dental clinic & $25(19.23)$ & $8(16.3)$ & $17(21)$ & \\
\hline & General medical practitioner & $2(1.54)$ & $1(2)$ & $1(1.2)$ & \\
\hline & Others & $11(8.46)$ & $2(4.1)$ & $9(11.1)$ & \\
\hline \multirow{4}{*}{$\begin{array}{l}\text { Measures to be taken in } \\
\text { bleeding gums }\end{array}$} & Stop brushing & $18(13.84)$ & $12(24.5)$ & $6(7.4)$ & \multirow{4}{*}{$0.023^{\mathrm{a}}$} \\
\hline & Go to see a dentist & $35(26.92)$ & $8(16.3)$ & $27(33.3)$ & \\
\hline & Pay more attention to gums when brushing & $33(25.38)$ & $13(26.5)$ & $20(24.7)$ & \\
\hline & Ignore bleeding & $44(33.84)$ & $16(32.7)$ & $28(34.6)$ & \\
\hline \multirow{3}{*}{$\begin{array}{l}\text { Measures to be taken in } \\
\text { tooth decay }\end{array}$} & Don't care if no pain & $44(33.84)$ & $21(42.9)$ & $23(28.4)$ & \multirow{3}{*}{$0.070^{\mathrm{a}}$} \\
\hline & Go to dentist immediately for filling & $11(8.46)$ & $6(12.2)$ & $5(6.2)$ & \\
\hline & Take pills for pain relief & $75(57.69)$ & $22(44.9)$ & $53(65.4)$ & \\
\hline \multirow{2}{*}{$\begin{array}{l}\text { There are harmful effects } \\
\text { of tobacco products }\end{array}$} & Yes & $49(37.69)$ & $46(93.9)$ & $3(6.1)$ & \multirow{2}{*}{$0.742^{\mathrm{b}}$} \\
\hline & No & $81(62.30)$ & $74(91.4)$ & $7(8.6)$ & \\
\hline
\end{tabular}


Dahal et al. Attitude, Behavior and Oral Health among Patients Visiting a Dental Institution..

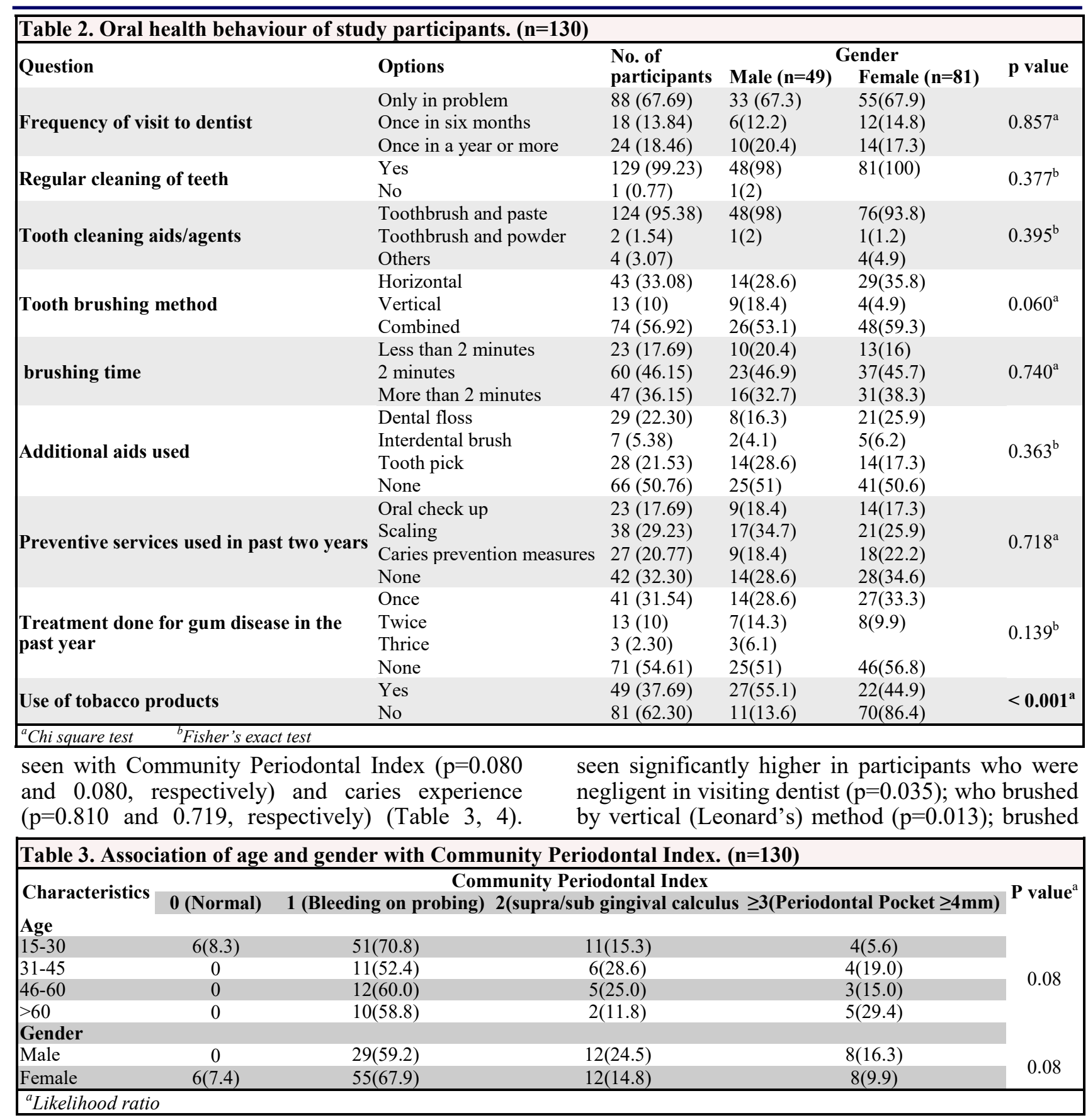

\begin{tabular}{|c|c|c|c|}
\hline \multicolumn{4}{|c|}{$\begin{array}{l}\text { Table 4. Association of age and gender with carie } \\
\text { experience. }(n=130)\end{array}$} \\
\hline \multirow{3}{*}{$\begin{array}{l}\text { Characteristics } \\
\text { Age }\end{array}$} & \multicolumn{2}{|c|}{ Caries experience } & \multirow{2}{*}{ P value ${ }^{a}$} \\
\hline & DMFT $=0$ & $\mathbf{D M F T} \geq 1$ & \\
\hline & & & \multirow{5}{*}{0.81} \\
\hline $15-30$ & $5(6.9)$ & $67(93.1)$ & \\
\hline $31-45$ & $2(9.5)$ & $19(90.5)$ & \\
\hline $46-60$ & $1(5.0)$ & $19(95.0)$ & \\
\hline$>60$ & $2(11.8)$ & $15(88.2)$ & \\
\hline \multicolumn{4}{|l|}{ Gender } \\
\hline Male & $6(12.2)$ & $43(87.8)$ & \multirow{2}{*}{0.176} \\
\hline Female & $4(4.9)$ & $77(95.1)$ & \\
\hline${ }^{a}$ Fisher's exact test & & square & \\
\hline
\end{tabular}

However, Loss of attachment was significantly developed in older age group $(\mathrm{p}<0.001)$ and in males $(\mathrm{p}=0.001)$ (Table 5). Loss of attachment was less than two minutes and more than five minutes $(\mathrm{p}=0.015)$; who used toothpicks or no inter dental cleaning aids $(\mathrm{p}=0.009)$; who ignored when gums were bleeding $(\mathrm{p}=<.001)$ and who used tobacco

\begin{tabular}{|c|c|c|c|}
\hline \multicolumn{4}{|c|}{$\begin{array}{l}\text { Table 5. Association of age and gender with loss of } \\
\text { attachment. }(n=130)\end{array}$} \\
\hline \multirow[b]{2}{*}{ Characteristics } & \multicolumn{2}{|c|}{ Loss of attachment } & \multirow[b]{2}{*}{$P$ value } \\
\hline & Score $0(0-3 \mathrm{~mm})$ & $\begin{array}{l}\text { Score } \geq 1(\geq \\
4 \mathrm{~mm})\end{array}$ & \\
\hline \multicolumn{3}{|l|}{ Age } & \multirow{5}{*}{$<0.001^{\mathrm{a}}$} \\
\hline $15-30$ & $66(91.7)$ & $6(8.3)$ & \\
\hline $31-45$ & 13(61.9) & $8(4.6)$ & \\
\hline $46-60$ & $4(20)$ & $16(80)$ & \\
\hline$>60$ & $2(11.8)$ & $15(88.2)$ & \\
\hline \multicolumn{3}{|l|}{ Gender } & \multirow{3}{*}{$0.001^{b}$} \\
\hline Male & 23(46.9) & $26(53.1)$ & \\
\hline Female & $62(76.5)$ & $19(23.5)$ & \\
\hline \multicolumn{2}{|c|}{${ }^{a}$ Fisher's exact test } & ${ }^{b}$ Chi square & \\
\hline
\end{tabular}


products $(\mathrm{p}<0.001)$.

\section{DISCUSSION}

Oral disease is one of the major public health problem. ${ }^{8,9}$ To spread awareness regarding the oral health, it is necessary to know about the attitude and behavior of the patient regarding the oral health. Therefore, the present study was designed to assess the attitude, behavior and oral health among the patients visiting Kathmandu Medical College, Bhaktapur for oral health check up.

The attitude and behaviour was similar among males and females surveyed regarding oral health. Majority $87(67 \%)$ of the participants generally visited the dentist only in problem even when they sensed that it is essential to visit in every six months for prevention of dental problems. This result is comparable to a study done among patients in Bir Hospita ${ }^{10}$ and Nursing students of Dhulikhel hospital. ${ }^{6}$ This may be because people of Nepal are not aware that regular oral health check up in every six months is essential even if they do not suffer from any symptoms of oral diseases. In the present study, majority of the study population $(99.2 \%)$ cleaned their teeth regularly which is slightly higher than a study done in Biratnagar (98\%); much better than study done among construction workers of Manglore. ${ }^{11,14}$ In this study $100 \%$ females and $98 \%$ males brushed regularly which is much pleasing than study done among attendants in South India where only $88 \%$ of females and $84 \%$ males brushed regularly. ${ }^{15}$ Most of the patients (95\%) visiting Kathmandu Medical College were using toothbrush and tooth paste for cleaning their teeth which is better than in a study done in India where $70 \%$ of the participants used tooth brush and tooth paste. ${ }^{4}$ Most of the study participants (55.5\%) agreed that oral hygiene maintenance is important because it prevents tooth decay. More than half of them (70.8\%) visited dental hospitals rather than dental clinics or general medical practitioner. It is disappointing to know that some of them $(32 \%)$ had never received prevention service in past two years. This could be due to decreased awareness of the dental problems, poor attitude in seeking dental service, as they are more likely to visit dentist for emergency dental care only.

Additional plaque control aids were used by almost half of the study participants including dental floss $(22.3 \%)$ tooth picks $(19.5 \%)$ which is better than the study conducted in China where $4 \%$ used dental floss and 36\% used tooth picks. ${ }^{7}$ Most of the subjects $(70 \%)$ would visit a dentist for bleeding gums and decayed tooth. More than half of the male participants $(55.1 \%)$ and $44.9 \%$ of females had used tobacco products in their life time either in smoking or smokeless form which is much higher than the study done among attendants in India where only $19.6 \%$ males and $27 \%$ females did so. ${ }^{15}$ Majority of the participants in this study (92\%) knew about the harmful effects of the tobacco use whereas very few $(10.9 \%)$ had idea about the ill-effects in the study conducted in Biratnagar, Nepal. ${ }^{11}$ Recently, the people of Nepal may have been aware of the harmful effects because of strict laws adopted by Nepal, ${ }^{12}$ different awareness programs in social media and the recent change in packaging of tobacco products where harmful effects are displayed.

The scientific literature provides us an overview regarding impact of oral health knowledge, attitude and oral health behavior on oral diseases. ${ }^{2}$ In this study, males showed significantly higher loss of attachment than females was associated with tobacco consumption similar to other studies done in a dental hospitals of Kathmandu. ${ }^{13,16}$ However, a study showed no difference in gender for periodontal conditions. ${ }^{5}$ In Nepal, smoking and smokeless tobacco production and consumption is higher that may be the major cause for periodontitis. Loss of attachment was observed more in older age group $(\mathrm{p}<0.001)$ similar to study done in a dental hospital of Nepal. ${ }^{5}$

Caries experience of the study participants (DMFT) was $3.85 \pm 3.035$ (median $=3$ ) with more of untreated caries $(2.28 \pm 2.121)$ than filled $(0.91 \pm 1.507)$. It is mainly because they visited dentist only when they have problems like pain or swelling, rather than treating in initial stage before symptoms appear. The caries experience is in accordance to the analysis of epidemiological data done in Nepal. ${ }^{17}$

This study has few limitations. Hospital based study has been conducted which cannot be generalized to overall population of Nepal. The hospital patients may have given answers that tend to overestimate their positive practices and underestimate their negative habits. Temporal relationship in the associated results could not be shown due to cross-sectional nature of the study.

\section{CONCLUSIONS}

This study concluded that the attitude towards the oral health was positive among the patients who visited Kathmandu Medical College, Duwakot, Bhaktapur. The oral health behaviour was quite unsatisfactory and needs to be improved. Repeated oral health awareness programs including oral health education and motivation in hospitals as well as community would help further develop their attitude and behaviour.

Conflict of Interest: None 
Dahal et al. Attitude, Behavior and Oral Health among Patients Visiting a Dental Institution..

\section{REFERENCES}

1. American Dental Association House of Delegates. ADA Policy: Definition of Oral Health. A American Dental Association; 2014 (cited in 2018 July 24).Available from https:// www.ada.org/en/about-the-ada/ada-positionspolicies-and-statements/ada-policy-definition-of -oral-health.

2. Bhattarai R, Khanal S, Rao GN, Shrestha S. Oral health related knowledge, attitude and practice among nursing students of Kathmandu -a pilot study. Journal of College of Medical Sciences-Nepal. 2016.12(4):160-8.

3. Scaglia P, Niknamdeh A. Assessment of current oral health knowledge attitude and oral hygiene practices among 12-year old school children and patients attending the dental facility at Vezo Hospital in the rural village of Andavadoaka, Madagascar. Malmö University. 2017;15:1-24.

4. Kaira LS, Srivastava V, Giri P, Chopra D. Oral Health-Related Knowledge, Attitude and Practice among Nursing Students of Rohilkhand Medical College and Hospital. J Orofac Res. 2012 Jan 25;2(1):20-3.

5. Rajkarnikar J, Acharya J. Prevalence and severity of periodontal diseases among Nepalese adults-a hospital based study. Journal of College of Medical Sciences-Nepal. 2014;10 (1):11-6. 7.

6. Humagain M, Tamrakar M. Oral health related knowledge, attitude and practice among nursing students of Dhulikhel hospital: A study. J Nepal Dent Assoc. 2010:11(2):117-12.

7. Zhu L, Petersen PE, Wang HY, Bian JY, Zhang BX. Oral health knowledge, attitudes and behavior of adults in China. Int Dent J. 2005 Aug;55(4):231-41.

8. Dumitrescu AL. Periodontal Disease-A Public Health Problem. Frontiers in public health. 2016 Jan 8;3:278.

9. Ekman A. Chapter 5.10: major public health problems - dental health. Scand J Public
Health. 2006 Jun;34(67_suppl):139-46.

10. Bhadra M. The knowledge, attitude and oral health behavior of adults attending Bir Hospital Dental Department. 2003.

11. Dali M, Laleet R. A Study on Oral Health Knowledge, Attitude and Practice among Population of Siswani Jahada VDC in Biratnagar City, Nepal-A Questionnaire Survey. Asian Pac J Health Sci. 2014.1:51-6.

12. Ministry of Health and Population. Tobacco Product Control and Regulatory Directive. Government of Nepal. 2014 (cited in February 1, 2018). Available from https:// www.tobaccocontrollaws.org/files/live/Nepal/ Nepal\%20\%20TP\%20Regs\%202014.pdf.

13. Gupta S, Maharjan A, Dhami B, Amgain P, Katwal S, Adhikari B, Shukla A. Status of Tobacco Smoking and Diabetes with Periodontal Disease. Journal of the Nepal Medical Association. 2018 Sep 1;56(213).

14. Bipina P, Kadam M, Mohammed N, Jain A. Awareness and Asssessment of Oral Hygeine and Periodontal Status among the Construction Workers in Aj Hospital Campus, Mangalore. International Journal of Current Research and Review. 2015 May 1;7(9):36.

15. Warad L, Pulayath CV, Baby M, Ismail SP. Assessment of Oral Health Knowledge, Dental Caries and Periodontal Status among Attendants of Degree Colleges in South India. Int J Oral Care Res. 2018;6(1):24-29.

16. Pradhan S, Bhat MK. Assessment of periodontal status of rural nepalese population using the community periodontal index. J Nepal Dent Assoc. 2009;10:97-104.

17. Van Palenstein Helderman W, Groeneveld A, Truin GJ, Shrestha BK, Bajracharya M, Stringer R. Analysis of epidemiological data on oral diseases in Nepal and the need for a nationa oral health survey. International dental journal. 1998 Feb;48(1):56-61.

Citation: Dahal S, Poudel P, Khadka N, Dahal S, Acharya M, Shrestha S, Maharjan M. Attitude, Behavior and Oral Health among Patients Visiting a Dental Institution of Nepal. JCMS Nepal. 2020; 16(1):44-8. 